\title{
IMPORTÂNCIA DA IMPLEMENTAÇÃO DO MANUAL DE POLÍCIA JUDICIÁRIA MILITAR NO CORPO DE BOMBEIROS MILITAR DE PERNAMBUCO
}

Rafael Queiroz de Almeida ${ }^{1}$

\section{RESUMO}

O Corpo de Bombeiros Militar de Pernambuco (CBMPE) tem como uma de suas missões precípuas a atividade de Polícia Judiciária Militar (PJM), a qual é alicerçada na investigação dos crimes militares praticados por integrantes da Corporação, além da execução de diligências e determinações requisitadas pela Justiça Militar Estadual e pelo Ministério Público. Todavia, não há norma interna que regulamente estas atividades, sendo assim, este artigo debate acerca da necessidade da implementação de um Manual de Polícia Judiciária Militar a ser aplicado ao CBMPE, como forma de padronizar no âmbito institucional o exercício, a delegação, as competências e as definições relacionadas ao crime militar, a fim de orientar a autuação e a instrução dos procedimentos, bem como, instrumentalizar o conjunto das peças processuais inerentes à atividade, quais sejam, Auto de Prisão em Flagrante Delito Militar (APFDM), Inquérito Policial Militar (IPM) e Instrução Provisória de Deserção (IPD), complementada pelo Auto de Captura de Desertor (ACD).

Palavras-chave: Bomberios; Implementação; Manual; Polícia Judiciária Militar.

1 Capitão do Corpo de Bombeiros Militar de Pernambuco, Graduado em Direito pelo Instituto de Ensino Superior de Olinda. E-mail: rafaelqabm@hotmail.com 


\title{
IMPORTANCE OF THE IMPLEMENTATION OF THE MILITARY JUDICIAL POLICE MANUAL IN THE FIRE DEPARTAMENT MILITARY OF PERNAMBUCO
}

\begin{abstract}
The Military Fire Brigade of Pernambuco (CBMPE) has as one of its main missions the activity of the Military Judicial Police (PJM), which is based on the investigation of military crimes committed by members of the Corporation, in addition to carrying out the required diligences and determinations by the State Military Justice and the Public Ministry. However, there is no internal rule that regulates these activities, therefore, this article debates about the need to implement a Military Judicial Police Manual to be applied to CBMPE, as a way to standardize the exercise, delegation, competences at the institutional level and the definitions related to military crime, in order to guide the assessment and the instruction of the procedures, as well as to do the set of procedural documents inherent to the activity, namely, Arrest Record in Flagrant Military Crime (APFDM), Military Police Inquiry (IPM) and Provisional Desertion Instruction (IPD), complemented by Deserter Capture Auto (ACD).
\end{abstract}

Keywords: Firefighters; Implementation; Manual; Military Judicial Police 


\section{INTRODUÇÃO}

O Corpo de Bombeiros Militar de Pernambuco (CBMPE) exerce suas funções em diversas áreas, conforme lhe impõe as legislações vigentes, dentre elas, as atribuições elencadas na Constituição Federal de 1988. Neste rol de competências, inclui-se a atividade legal de Polícia Judiciária Militar (PJM), inerente às instituições militares, sejam federais ou estaduais. Desta feita, percebe-se que a Corporação não possui normativo para nortear a atuação dos oficiais no exercício das funções de investigação dos crimes militares praticados pelos seus integrantes, recaindo-se na necessidade de regulamentação da atividade, visto que é de fundamental importância na busca pela padronização dos documentos necessários à formalização dos atos de persecução criminal no âmbito do CBMPE.

O termo Polícia Judiciária Militar está diretamente relacionado à existência da Justiça Militar, a qual está prevista na Constituição Federal de 1988, por meio dos artigos 122, 123 e 124. Sua função precípua é a apuração da materialidade e autoria de crimes militares, bem como o auxílio ao Poder Judiciário no cumprimento de diligências relacionadas à atividade jurisdicional militar, tais como, mandados de prisão, busca e apreensão, conduções coercitivas, elaboração de procedimentos, dentre outras (NEVES, 2021).

A atuação da Justiça Militar Estadual está descrita no § 4º, artigo 125 da Carta Magna, quando define que compete à Justiça Militar Estadual processar e julgar os militares dos Estados, nos crimes militares definidos em lei e as ações judiciais contra atos disciplinares militares, ressalvada a competência do júri quando a vítima for civil, cabendo ao tribunal competente decidir sobre a perda de posto e da patente dos oficiais e da graduação das praças (BRASIL, 1988).

A competência para julgar os crimes militares se encontra descrita, de forma implícita, nos termos do $\S 4^{\circ}$, art. 144 da Constituição Federal de 1988, quando o legislador define a atribuição da Polícia Civil para apuração de 
infrações penais, além de dispor acerca das prerrogativas de polícia judiciária de forma geral, excetuando-se do âmbito das polícias civis dos Estados os crimes militares, cabendo ressaltar que em relação à União, a atribuição é da Polícia Federal (BRASIL, 1988).

Neste diapasão, ao analisar o texto constitucional do artigo 144, § 4ํㅡㅇ o raciocínio possível é que os atos de polícia judiciária relacionados aos crimes classificados pela lei como militares são atribuídos às próprias forças militares, quais sejam, Aeronáutica, Marinha e Exército, no âmbito federal, e às Polícias e Corpos de Bombeiros Militares, no âmbito dos estados e do Distrito Federal (BRASIL, 1988).

As atividades de Polícia Judiciária Militar têm sua atuação regida pelo Código de Processo Penal Militar (CPPM), dentre outros dispositivos legais, predominando o seu caráter repressivo, já que sua principal função é apurar a prática do ilícito penal militar, atuando como auxiliar da Justiça Militar (CBMMT, 2017).

A implementação do Manual de PJM tem o escopo de padronizar os procedimentos, a fim de que a doutrina jurídica seja fomentada na instituição, além de proporcionar o cumprimento das legislações vigentes de forma técnica, respeitando os preceitos instrumentais das leis processuais. Ressalta-se a premente necessidade do normativo ser pautado na Constituição Federal de 1988, Código Penal Militar e Código de Processo Penal Militar, normas essas que regulamentam a atividade criminal no âmbito das Corporações Militares Estaduais.

Os procedimentos de persecução criminal dispostos do CPPM, e usualmente instrumentalizados no CBMPE, são o Auto de Prisão em Flagrante Delito Militar (APFDM), Inquérito Policial Militar (IPM) e a Instrução Provisória de Deserção (IPD). Neste sentido, e com o objetivo de delimitar a demanda de instrumentos desta natureza, fez-se a análise quantitativa de procedimentos instruídos no CBMPE por um determinado decurso temporal, como forma de dimensionar a atividade jurisdicional na instituição. Além disso, foram 
analisadas as normas vigentes em outras instituições, a fim de debater se existem Manuais de Polícia Judiciária Militar sendo utilizados em âmbito nacional, elencando os possíveis ganhos institucionais no sentido de implantar norma que fomente sua doutrina jurídica.

\section{OBJETIVOS}

- Descrever as atribuições do exercício de Polícia Judiciária Militar;

- Analisar a necessidade da implementação do Manual de Polícia Judiciária no CBMPE.

\section{METODOLOGIA}

Para a escrita deste artigo, utilizou-se a pesquisa exploratória, buscando avaliar a doutrina jurídica já existente sobre o tema, com fulcro a averiguar os pormenores acerca dos procedimentos de persecução criminal estabelecidos pela legislação vigente, bem como, aplicados nas instituições militares, facilitando-se assim a formulação de novos problemas e propondo soluções viáveis.

Partindo deste pressuposto, foram analisados Manuais de Polícia Judiciária Militar de outras instituições, tais como de Corpos de Bombeiros e Polícias Militares de outros Estados, além da Polícia Militar de Pernambuco e Ministério da Defesa. Desta forma, foi discutida a necessidade de se formular normativa própria, lastreada também, pela legislação constitucional e penal militar, a fim de se debater acerca dos benefícios da padronização dos procedimentos e das peças de Polícia Judiciária Militar.

Como forma de sopesar o panorama institucional, foram quantificados os procedimentos instruídos na Corporação do ano de 2016 ao ano de 2020, através dos dados constantes no Sistema Integrado de Gestão de Processos Administrativos (SIGPAD), sendo esta ferramenta utilizada para a gestão dos processos administrativos disciplinares e dos procedimentos de Polícia 
Judiciária Militar no âmbito da Secretaria de Defesa Social do Estado de Pernambuco, da qual o CBMPE é um dos órgãos operativos. Tal levantamento teve o intuito de delimitar a demanda de procedimentos investigatórios de PJM que foram instruídos, bem como os mais utilizados no decurso temporal de 05 (cinco) anos, a fim de demonstrar a necessidade de criar-se doutrina jurídica institucional.

\section{POLÍCIA JUDICIÁRIA MILITAR}

De proêmio, faz-se necessário compreender a quem cabe o exercício de PJM na caserna, neste sentido, Gorrilhas e Britto (2016) destacam que as atribuições dos oficiais não estão expressamente previstas na Constituição Federal, conforme estão as da Polícia Civil e da Polícia Federal, desta forma, o respaldo para as atribuições de funções investigativas de crimes militares estão assentadas no CPPM. As competências inerentes a PJM estão descritas em seu artigo $8^{\circ}$, quais sejam:

Art. $8^{\circ}$ Compete à Polícia judiciária militar:

a) apurar os crimes militares, bem como os que, por lei especial, estão sujeitos à jurisdição militar, e sua autoria;

b) prestar aos órgãos e juízes da Justiça Militar e aos membros do Ministério Público as informações necessárias à instrução e julgamento dos processos, bem como realizar as diligências que por eles (sic) Ihe forem requisitadas;

c) cumprir os mandados de prisão expedidos pela Justiça Militar;

d) representar a autoridades judiciárias militares acerca (sic) da prisão preventiva e da insanidade mental do indiciado;

e) cumprir as determinações da Justiça Militar relativas aos presos sob sua guarda e responsabilidade, bem como as demais prescrições deste (sic) Código, nesse sentido;

f) solicitar das autoridades civis as informações e medidas que julgar úteis à elucidação das infrações penais, que esteja a seu cargo;

g) requisitar da polícia civil e das repartições técnicas civis as pesquisas e exames necessários ao complemento e subsídio de inquérito policial militar;

h) atender, com observância dos regulamentos militares, a pedido de apresentação de militar ou funcionário de repartição militar à autoridade civil competente, desde que legal e fundamentado o pedido. (BRASIL, 1969) 
Conforme aduzem Dias e Barbosa (2018), através dos procedimentos de PJM, na chamada fase pré-processual, o oficial encarregado deverá proceder à colheita de elementos de informações, na busca por autoria e materialidade do delito militar, a fim de oferecer subsídios para que o titular da ação penal pública, qual seja, o Ministério Público, ofereça a denúncia ao Juiz Militar.

Neste aspecto, pode-se conceituá-la como sendo uma atividade exercida pela autoridade militar, com a finalidade de apurar as infrações penais militares, buscando sua autoria e materialidade, para que o Ministério Público tenha subsídios para propositura da ação penal, além de outras, em apoio e auxílio à autoridade judiciária (MANOEL, 2005).

Ademais, no entendimento de Roth (2016), a Polícia Judiciária Militar é aquela polícia que realiza um complexo de atividades voltadas à repressão das infrações penais militares, exercendo seu poder de polícia, como a realização de investigações, dos inquéritos policiais militares, dos autos de prisão em flagrante delito, da instrução provisória de deserção ou de insubmissão, e assim atuando como auxiliar da Justiça Militar.

\section{CRIME MILITAR}

Para ser considerado crime militar, o fato deve ser devidamente tipificado, estando na parte especial do Código Penal Militar (CPM) ou na legislação penal comum. Confirmada a tipificação, faz-se necessário a adequação da conduta nos artigos 9o e 10 do citado código, nos casos de crimes militares em tempo de paz e em tempos de guerra, respectivamente (NEVES, 2014).

Outrossim, antes do advento da Lei ㄲo 13.491, de 13 de outubro de 2017, só eram considerados crimes militares em tempo de paz as condutas tipificadas na parte especial do CPM, mesmo que praticadas no exercício da função. Entretanto, com a promulgação da supracitada lei, o artigo 9o, inciso II do CPM foi alterado, passando-se a considerar crimes militares os também 
elencados na legislação penal comum, praticados nas condições descritas neste artigo, sendo denominados pela doutrina de crimes militares por extensão ou crimes militares extravagantes (NEVES, 2014).

Neste diapasão, pode-se destacar o magistério de Ribeiro (2017), quando difere o crime militar em propriamente militar e impropriamente militar, fruto do critério ratione legis, ou seja, insculpido na lei. O crime propriamente militar também é chamado de crime militar puro ou crime militar próprio, enquanto que o crime impropriamente militar pode ser denominado de crime militar impuro ou crime militar impróprio, salientando-se que a classificação tem o escopo de analisar a norma penal e não a conduta do agente.

Há dois entendimentos diversos acerca da definição de crime propriamente militar. O primeiro aduz que é o tipo de crime que apenas está previsto na legislação penal militar e somente o militar pode ser o sujeito ativo. Entretanto, o segundo entendimento prevê que esta definição vai de encontro ao disposto no próprio inciso I, do artigo 9o do Código Penal Militar, considerando que o crime de insubmissão, por exemplo, está previsto apenas no CPM e o agente só pode ser civil, sendo um exemplo claro de crime propriamente militar, por estar previsto apenas no CPM, mas cometido, necessariamente, por civil e nem por isso deixa de ser crime propriamente militar (SARAIVA, 2014).

A Carta Magna menciona explicitamente a denominação propriamente militar, em seu inciso LXI, do artigo $5^{\circ}$, quando define que:

LXI - ninguém será preso senão em flagrante delito ou por ordem escrita e fundamentada de autoridade judiciária competente, salvo nos casos de transgressão militar ou crime propriamente militar, definidos em lei. (BRASIL, 1988)

Nessa toada, para definir-se se o crime é propriamente militar há a necessidade de analisar a norma na qual a conduta está prevista, se estiver descrita exclusivamente no CPM, qualquer que seja o agente, tem-se o crime propriamente militar. Mesmo que o crime esteja apenas previsto no CPM e tenha sido cometido por civil, não desnatura-se a natureza de crime 
propriamente militar. Sendo assim, os crimes militares previstos apenas no citado código, quais sejam, os crimes propriamente militares, e que são cometidos por civis, como a insubmissão, criação ou simulação de incapacidade física e substituição a convocação, são considerados crimes militares (SARAIVA, 2014).

Esta conceituação está implícita, mesmo que de forma indireta, no inciso I, do artigo $9^{\circ}$ do CPM, quando assenta que são crimes militares "os crimes de que trata este Código, quando definidos de modo diverso na lei penal comum, ou nela não previstos, qualquer que seja o agente, salvo disposição especial' (BRASIL, 1969).

Após a conceituação do crime propriamente militar, observa-se que o crime impropriamente militar é aquele em que a tipificação da conduta está descrita no CPM, mas que também está previsto, com idêntica descrição, na legislação penal comum, sendo praticado nas condicionantes descritas no inciso II, do artigo 9o do CPM, nestes termos (SARAIVA, 2014):

\section{Crimes militares em tempo de paz}

Art. 9 Consideram-se crimes militares, em tempo de paz:

(...)

II - os crimes previstos neste Código e os previstos na legislação penal, quando praticados:

a) por militar em situação de atividade ou assemelhado, contra militar na mesma situação ou assemelhado;

b) por militar em situação de atividade ou assemelhado, em lugar sujeito à administração militar, contra militar da reserva, ou reformado, ou assemelhado, ou civil;

c) por militar em serviço ou atuando em razão da função, em comissão de natureza militar, ou em formatura, ainda que fora do lugar sujeito à administração militar contra militar da reserva, ou reformado, ou civil;

d) por militar durante o período de manobras ou exercício, contra militar da reserva, ou reformado, ou assemelhado, ou civil;

e) por militar em situação de atividade, ou assemelhado, contra o patrimônio sob a administração militar, ou a ordem administrativa militar;

f) revogada. (BRASIL, 1969)

Logo, em conformidade com o Manual de Autuação em Flagrante Delito Militar (MAFDM) da Corregedoria Geral da Secretaria de Defesa Social de 
Pernambuco, pode-se denominar o crime impropriamente militar, de crime militar impuro ou crime militar impróprio, sendo conceituado no artigo 9o, inciso II do CPM, o qual se caracteriza quando a conduta estiver tipificada tanto no CPM quanto na legislação penal comum, de modo idêntico, e o sujeito do delito for militar da ativa, nas condições elencadas pela mencionada norma. Neste sentido, enquanto os crimes propriamente militares estão elencados no inciso I, artigo 9o do CPM, não existindo uma condição jurídica específica para o agente, podendo ser praticado inclusive por militares inativos ou civis, já em relação à norma do inciso II, do artigo $9^{\circ}$ do CPM, há a necessidade de que 0 sujeito ativo seja militar em situação de atividade, não aplicando-se aos militares inativos ou civis (MAFDM, 2018).

Com fulcro a exemplificar os crimes impropriamente militares, podemos mencionar que o CPM possui, na sua parte especial, em tempo de paz, os crimes de furto, roubo, dano, apropriação indébita, estelionato, receptação, homicídio culposo, lesão corporal dolosa, lesão corporal culposa, peculato doloso e culposo, dentre outros, com a mesma definição do Código Penal Brasileiro (MAFDM, 2018).

Sobrevela ressaltar, que com o advento da já citada norma, e as consequentes alterações por ela trazidas no artigo $9^{\circ}$ do CPM, a competência da Justiça Militar, nas esferas federal, estadual e distrital, foi ampliada. A modificação operada na norma do inciso II, do artigo 9ำ do CPM, ampliou as figuras típicas que possam compor o rol dos crimes militares. Isso porque, além dos crimes militares definidos no CPM, serão, também, crimes militares em tempo de paz os previstos na legislação penal comum quando praticados conforme uma das circunstâncias contidas nas alíneas do inciso II, do artigo 9oㅡㅁ do CPM (MAFDM, 2018).

Sem embargo, cabe registrar que essa mudança realizada pela Lei Federal ํo 13.491/2017 não ocorreu no inciso III, do artigo 9o do CPM, apenas no inciso II. Entrementes, a norma do inciso III faz menção ao inciso I e ao inciso II, razão pela qual é alcançado, o inciso III, do artigo 9ำ do CPM, pela 
alteração operada no inciso II, do mencionado artigo. Desta forma, o crime que originalmente seria de natureza jurídica comum, pois é previsto na legislação penal comum, passou a ser crime militar quando for praticado por militar nas condições e circunstâncias previstas em uma das alíneas do inciso II, artigo 9o do CPM, excetuando-se os crimes dolosos contra a vida de civil, conforme $\S 1^{\circ}$, do artigo 9०, do CPM, que relata: "Os crimes de que trata este artigo, quando dolosos contra a vida e cometidos por militares contra civil, serão da competência do Tribunal do Júri" (MAFDM, 2018, apud BRASIL, 1969).

Esses crimes militares, cometidos nas condições do inciso II, do artigo 9o do CPM, mas que não estão previstos em sua parte especial, e sim previstos na lei penal comum, são denominados crimes militares extravagantes ou crimes militares por extensão. Essa nomenclatura foi adotada pela doutrina para os crimes militares não previstos no CPM, mas previstos na lei penal comum, extravagante ao CPM, quando praticados nas condições do inciso II, do artigo 9을 do CPM (MAFDM, 2018).

Dito isto, Almeida (2019) relata que o art. 9ำ do CPM possui três artigos, que em apertada síntese se estrutura da seguinte forma:

1) o inciso I, do artigo 9o do CPM, dedica-se aos casos de crimes propriamente militares, que são aqueles previstos apenas no Código Penal Militar;

2) 0 inciso II, do artigo 9 do CPM, trata-se dos crimes impropriamente militares e crimes militares extravagantes praticados por militares da ativa;

3) o inciso III, do artigo 9 do CPM, dispõe sobre os crimes propriamente e impropriamente militares, bem como os militares por extensão, praticados na esfera estadual por militares da reserva e reformados, considerando que tal inciso elenca os institutos dos incisos I e II.

\section{AUTORIDADE MILITAR}


O estudo sobre a implantação do Manual de Polícia Judiciária Militar tem o sentido de nortear a atuação das autoridades de PJM. Sendo assim, é de fundamental importância a compreensão de quem são essas autoridades, as quais estão elencadas no artigo $7^{\circ}$ do CPPM:

Art. $7^{\circ}$ A polícia judiciária militar é exercida nos termos do art. 8ㅜㅡ, pelas seguintes autoridades, conforme as respectivas jurisdições:

a) pelos ministros da Marinha, do Exército e da Aeronáutica, em todo o território nacional e fora dele, em relação às fôrças e órgãos que constituem seus Ministérios, bem como a militares que, neste caráter, desempenhem missão oficial, permanente ou transitória, em país estrangeiro;

b) pelo chefe do Estado-Maior das Fôrças Armadas, em relação a entidades que, por disposição legal, estejam sob sua jurisdição;

c) pelos chefes de Estado-Maior e pelo secretário-geral da Marinha, nos órgãos, fôrças e unidades que lhes são subordinados;

d) pelos comandantes de Exército e pelo comandante-chefe da Esquadra, nos órgãos, fôrças e unidades compreendidos no âmbito da respectiva ação de comando;

e) pelos comandantes de Região Militar, Distrito Naval ou Zona Aérea, nos órgãos e unidades dos respectivos territórios;

f) pelo secretário do Ministério do Exército e pelo chefe de Gabinete do Ministério da Aeronáutica, nos órgãos e serviços que lhes são subordinados;

g) pelos diretores e chefes de órgãos, repartições, estabelecimentos ou serviços previstos nas leis de organização básica da Marinha, do Exército e da Aeronáutica;

h) pelos comandantes de fôrças, unidades ou navios; (BRASIL, 1969)

Conforme aduz Neves (2014), é essencial fazer adaptações no enunciado do artigo $7^{\circ}$ do CPPM, a fim de definir, por analogia, as autoridades de Polícia Judiciária Militar no âmbito das Corporações militares estaduais. Desta forma, nas Polícias e Corpos de Bombeiros Militares dos Estados são consideradas autoridades de PJM os Comandantes das Corporações e das suas Unidades, especificamente, os Comandantes Gerais, Subcomandantes Gerais, ou Chefes de Estado Maior, e os diversos Comandantes de Unidades.

Neste sentido, Alferes (2013, p. 33), assenta que "sua aplicação às Polícias Militares e Bombeiros Militares, estaduais ou do Distrito Federal, carece de adaptações ou norma de equiparação, pois o cargo e a função não são equivalentes, apesar da semelhança". 
No entanto, a correlação é aplicada usualmente às Corporações estaduais, neste diapasão, sobrevela ressaltar que as autoridades mencionadas possuem a competência originária, todavia, podem delegá-la aos oficiais da ativa, resultando na competência delegada, nos termos do artigo 7ํㅡ, $\S 1^{\circ}$ do CPPM, o qual define:

Art. 7ํㅡ A polícia judiciária militar é exercida nos termos (sic) do art. 8ㅜㅡ, pelas seguintes autoridades, conforme as respectivas jurisdições:

(...)

$\S 1^{\circ}$ Obedecidas as normas regulamentares de jurisdição, hierarquia e comando, as atribuições enumeradas neste artigo poderão ser delegadas a oficiais da ativa, para fins especificados e por tempo limitado. (BRASIL, 1969)

Desta forma, o exercício de autoridade de PJM recairá, originariamente, aos Comandantes Gerais, Subcomandantes Gerais e Comandantes de unidades, e de forma delegada, aos oficiais da ativa.

\section{TIPOS DE PROCEDIMENTOS DE POLÍCIA JUDICIÁRIA MILITAR}

Os principais procedimentos previstos no CPPM são o Inquérito Policial Militar (IPM), o Auto de Prisão em Flagrante Delito Militar (APFDM) e a Instrução Provisória de Deserção (IPD), a qual é complementada por meio do Auto de Captura de Desertor (ACD).

Assim sendo, os citados procedimentos estão deslindados no CPPM, por meio do seguinte arcabouço normativo: o APFDM está previsto nos arts. 243 ao 253; o IPM está descrito do art. 9ำ ao 28; e a IPD está regulamentada do art. 451 ao 457 (DIAS; BARBOSA, 2018).

\section{MANUAL DE POLÍCIA JUDICIÁRIA MILITAR NO CBMPE}

Não há no CBMPE nenhum Manual de PJM regulamentado, neste sentido, a atuação dos oficiais encarregados pelos procedimentos está 
baseada nas legislações penal e processual penal militar, bem como, em manuais de outras instituições, como o da Polícia Militar de Pernambuco.

Neste linde, a atuação dos oficiais da Corporação resta-se por prejudicada, devido à ausência de doutrina para a instrução, além de inexistirem modelos das peças processuais. Soma-se a isto, a falta de formação jurídica, a qual não é exigida por lei para o ingresso no Curso de Formação de Oficiais, o qual tem como requisito que o candidato possua formação em curso superior de qualquer área de atuação. Ademais, a grande rotatividade de funções resulta na ausência de especialização na atividade investigativa.

Corroborando a isto, Alferes (2013) se refere a uma narrativa proferida pelo Conselho Nacional de Procuradores Gerais Estaduais e da União (CNPG):

\footnotetext{
"a alta rotatividade de oficiais e acúmulo de funções faz com que raramente algum oficial chegue a adquirir experiência na função de investigar, deixando a qualidade da investigação totalmente na dependência da sorte de o encarregado ter perfil, conhecimento e tempo para um bom trabalho. (...)" (ALFERES, 2013)
}

Logo, as Polícias e os Corpos de Bombeiros Militares têm a necessidade de positivar suas normas, principalmente, em virtude da variação cultural e dos vários focos de atuação, devendo buscar um norteamento e padronização de procedimentos, visto que a sociedade não pode receber um serviço com base no improviso (DIAS, 2018).

Assim, a implantação do Manual de PJM será uma forma de sistematização, padronização de procedimentos, orientação e norteamento para os oficiais que atuam na função de investigar os crimes militares. A positivação desse norteamento trará profissionalismo, técnica e uniformidade na confecção de procedimentos para os oficiais que atuam nas diversas funções relacionadas ao tema em debate (DIAS, 2018). 


\section{MANUAL DE POLÍCIA JUDICIÁRIA MILITAR EM OUTRAS INSTITUIÇÕES}

No âmbito nacional, várias instituições militares possuem o Manual de Polícia Judiciária Militar devidamente normatizado. Após a devida análise, verificou-se a vigência nas seguintes Corporações:

1) Manual de Polícia Judiciária Militar do Ministério da Defesa, publicado em junho de 2019, através da colaboração do Ministério Público Militar, Ministério da Defesa, Marinha do Brasil, Exército Brasileiro e Força Aérea Brasileira;

2) Manual de Polícia Judiciária Militar da Polícia Militar de Pernambuco (PMPE), publicado em 24 de janeiro de 2019 pela Polícia Militar de Pernambuco (PMPE);

3) Polícia Judiciária Militar - Manual de Processos e Procedimentos, publicado no ano de 2017 pelo Corpo de Bombeiros Militar do Mato Grosso (CBMMT);

4) Manual de Auto de Prisão em Flagrante Delito, publicado no ano de 2017 pelo Corpo de Bombeiros Militar do Espírito Santo (CBMES);

5) Manual de Procedimentos de Polícia Judiciária Militar e de Polícia Administrativa Disciplinar, publicado em 15 de maio de 2014 pelo Corpo de Bombeiros Militar de Sergipe (CBMSE); e

6) Manual de Prática de Polícia Judiciária Militar, publicado em 18 de junho de 2013 pela Polícia Militar do Piauí (PMPI).

Desta forma, vislumbra-se a necessidade de haver a regulamentação da atividade de PJM nas instituições, conforme ínsito no Manual de Polícia Judiciária Militar do Ministério da Defesa (2019), quando assenta que percebeu-se a necessidade de se ter, no âmbito da Justiça Militar da União, um modus operandi que permita a padronização de procedimentos de Polícia Judiciária Militar, com a finalidade de se estabelecer um normativo, um modelo na investigação criminal militar. Desta forma, o Ministério Público Militar 
procurou o Ministério da Defesa e as três Forças, com a ideia de desenvolver um projeto integrado, com a contribuição de todos os partícipes do procedimento, combinando teoria, por meio do detalhamento de cada etapa da investigação, com a prática, com a disponibilização de exemplos de documentos gerados. Assim, surgiu o Grupo de Estudos de Unificação dos Procedimentos de Polícia Judiciária Militar, o qual desenvolveu todo o trabalho.

Destaca-se no Manual de Processos e Procedimentos do CBMMT (2017), que a falta de conhecimento jurídico era, com raras exceções, uma regra na instituição, que trazia como consequências, Inquéritos Policiais Militares mal elaborados, com falhas que, na maioria dos casos, acabavam trazendo graves prejuízos à defesa, à administração pública e aos cidadãos.

Em consonância, o Manual de Prática de Polícia Judiciária Militar da PMPI (2013), define que tal norma disponibiliza os instrumentos doutrinários necessários à prática de PJM, resgatando informações balizadas, nascidas das experiências vividas por vários oficiais, sendo essencial à atividade jurisdicional.

\section{RESULTADOS E DISCUSSÕES}

A fim de sustentar a temática acerca da importância da implementação do Manual de PJM no âmbito do CBMPE, verificou-se, por meio de levantamento de dados inseridos no Sistema Integrado de Gestão de Processos Administrativos (SIGPAD), a quantidade de procedimentos instaurados na Corporação.

O SIGPAD é a ferramenta implantada no âmbito da Secretaria de Defesa Social, por meio da Portaria do Corregedor Geral № 672, de 30 de novembro de 2015, a qual deliberou pela obrigatoriedade da inclusão dos dados relativos a processos administrativos e procedimentos de PJM no sistema a partir do ano de 2015, através do seu $\S 3^{\circ}$, artigo $1^{\circ}$, nestes termos: 
Art.1ํㅡㄹ Determinar que as Portarias, Relatórios e Soluções de Processos Administrativos Disciplinares, bem como aqueles procedimentos a que se refere 0 art. 13 da Lei 11.929/01, devem ser enviados eletronicamente através do SIGPAD, obedecendo 0 cronograma de inserção das operativas.

(...)

$\S 3^{\circ}$ Os Comandantes, chefes e Diretores com competência para instaurar Sindicâncias, IPM, APFDM ou IPD, devem encaminhar por ofício nome completo, Matrícula, CPF, e-mail institucional de dois militares nomeados para alimentação do sistema em sua Unidade. (PCG, 2015)

Faz-se mister ressaltar, que a normatização que disciplina a utilização do SIGPAD foi atualizada, através da publicação do Provimento Correcional no 007, de 18 de março de 2019, o qual enfatizou a obrigatoriedade do lançamento de informações decorrentes de procedimentos disciplinares no sistema, conforme relatado em seu artigo 1을

Art. 1․ O presente Provimento Correicional tem o objetivo de ratificar a obrigatoriedade do lançamento de informações decorrentes de Processos Disciplinares no Sistema Integrado de Gestão de Processos Administrativos Disciplinares (SIGPAD), no âmbito da Corregedoria Geral e órgãos operativos da SDS, bem como definir e estabelecer atribuições para o aperfeiçoamento do fluxo e do registro no referido sistema eletrônico. (PC, 2019)

Para a contabilização dos procedimentos de PJM instruídos exclusivamente no âmbito do CBMPE, foi feita uma busca avançada no SIGPAD, delimitando a quantidade de Autos de Prisão em Flagrante Delito Militar (APFDM), Inquéritos Policiais Militares (IPM) e Instruções Provisórias de Deserção (IPD) inseridas no sistema entre os anos de 2016 e 2020, considerando que no ano de 2015, quando houve a implantação da ferramenta, a inclusão dos dados só iniciou-se a partir do mês de novembro, acarretando prejuízo para o cômputo. Dos dados extraídos, chegou-se ao seguinte montante:

Tabela 1 - Quantitativo de Procedimentos de PJM entre os anos de 2016 e 2020 
Revista FLAMMAE

Revista Científica do Corpo de Bombeiros Militar de Pernambuco

Artigo Publicado no Vol.07 N.19 - Julho a Dezembro 2021 - ISSN 2359-4829

Versão on-line disponível em: http://www.revistaflammae.com

\begin{tabular}{cccccc}
\hline & $\mathbf{2 0 1 6}$ & $\mathbf{2 0 1 7}$ & $\mathbf{2 0 1 8}$ & $\mathbf{2 0 1 9}$ & $\mathbf{2 0 2 0}$ \\
\hline IPM & 9 & 3 & 7 & 4 & 2 \\
APFDM & 0 & 0 & 2 & 0 & 1 \\
IPD & 0 & 0 & 0 & 0 & 1 \\
\hline
\end{tabular}

Fonte: Sistema Integrado de Gestão de Processos Administrativos (SIGPAD)

É notório que o IPM é o procedimento mais instrumentalizado no âmbito do CBMPE, totalizando vinte e cinco entre os anos de 2016 e 2020, ultrapassando assim o quantitativo de APFDM e IPD, os quais tiveram os montantes de três e um, respectivamente. Destarte, a instrução correta dos procedimentos é condição essencial para que o Ministério Público possa propor denúncia à Justiça Militar Estadual, assim ocorrendo a devida persecução criminal.

O conhecimento jurídico para a instrução de todas as peças processuais é de extrema importância para os oficiais da Corporação, tanto pelo zelo com a coisa pública, devendo investigar os fatos com a maior proficiência possível, quanto pelas implicações penais ou administrativas decorrentes de erros ou procrastinação por parte do encarregado, o qual poderá sofrer sanções penais ou administrativas, conforme o caso, a exemplo das tipificações constantes no artigo 319 do Código Penal Militar, e artigos 123 e 139 do Código Disciplinar dos Militares do Estado de Pernambuco (CDMEPE), conforme redação:

\footnotetext{
Código Penal Militar

Prevaricação

Art. 319. Retardar ou deixar de praticar, indevidamente, ato de ofício, ou praticá-lo contra expressa disposição de lei, para satisfazer interesse (sic) ou sentimento pessoal:

Pena - detenção, de seis meses a dois anos. (BRASIL, 1969, art. 319)

(...)

Código Disciplinar dos Militares do Estado de Pernambuco

Art. 123. Dificultar ou retardar, deixando de concluir no prazo legal, a solução ou andamento de documento, parte, recurso, prestação de informação, processo administrativo, inquérito, sindicância, diligências ou cumprimento de determinação judicial, que the competir, desde que não constitua crime.

Pena: Prisão, de 21 a 30 dias.
} 


\section{(...)}

Art. 139. Deixar de cumprir ou de fazer cumprir as normas regulamentares na esfera de suas atribuições.

Pena: Detenção, de 21 a 30 dias. (PERNAMBUCO, 2000)

Assim sendo, verifica-se que a atividade de PJM é amplamente aplicada ao CBMPE, nas diversas unidades da Região Metropolitana do Recife e do interior do Estado, ensejando-se na necessidade de implantação de uma norma regulamentadora na Corporação, a fim de orientar a instrução dos procedimentos, de modo a gerar doutrina institucional no viés jurídico.

\section{CONSIDERAÇÕES FINAIS}

Conclui-se que a Corporação não dispõe de norma orientadora relativa aos procedimentos de Polícia Judiciária Militar, tendo que subsidiar-se, por vezes, de Manuais elaborados por outras instituições, o que gera desuniformização e ausência de doutrina. Desta forma, este artigo buscou fomentar o debate acerca da atividade jurídica institucional, ressaltando-se a necessidade de implementação de norma orientadora para os militares imbuídos na atividade, a fim de servir como esteio na busca pelo conhecimento do exercício de Polícia Judiciária Militar.

Sobrevela destacar, que o exercício de Polícia Judiciária Militar é inerente as autoridades elencadas no art. $7^{\circ}$ do CPPM, que por analogia, recai sobre o Comandante Geral, Subcomandante Geral e Comandantes de unidades, de forma originária, e sobre os oficiais da ativa, de forma delegada, autoridades estas que detêm a competência de investigar os crimes militares, missão exclusiva das instituições militares (DIAS; BARBOSA, 2018).

A implementação do Manual de Polícia Judiciária Militar no âmbito do CBMPE contribuirá na instrumentalização do Auto de Prisão em Flagrante Delito Militar (APFDM), Inquérito Policial Militar (IPM) e Instrução Provisória de Deserção (IPD), este último sendo complementado pelo Auto de Captura de Desertor (ACD), atividades inerentes às forças militares. Tais procedimentos 
possuem normatização no CPPM, cabendo ao encarregado seguir os ritos e os procedimentos perpetrados por tal Código.

Em decorrência das deliberações elencadas pelo CPPM, o qual foi concebido no âmbito das Forças Armadas, mas que também é aplicado às Polícias e Corpos de Bombeiros Militares, faz-se fundamental a existência nas Corporações Militares Estaduais de normas internas que recepcionem o Código de modo a instrumentalizá-lo, conforme suas realidades institucionais, desta forma, difundindo as orientações jurídicas, que são imprescindíveis, com fulcro a propagar o conhecimento, além de sanear as indagações quanto a competência e atos processuais.

Como forma de verificar a abrangência do exercício de PJM no CBMPE, foi realizada a análise do quantitativo de procedimentos instaurados entre os anos de 2016 e 2020, por meio do sistema SIGPAD, o qual foi implementado pela Corregedoria Geral da Secretaria de Defesa Social de Pernambuco, visando a gestão dos processos administrativos e procedimentos de PJM na PMPE, CBMPE e Corregedoria Geral da SDS. Da análise, restou-se apurado o montante de vinte e cinco Inquéritos Policiais Militares, três Autos de Prisão em Flagrante Delito Militar e uma Instrução Provisória de Deserção, todos instaurados e instruídos no âmbito do CBMPE. Evidencia-se assim, que a atividade é uma missão precípua da Corporação, ensejando a necessidade de regulamentação específica para que se proceda de forma técnica.

Quanto a vigência de Manuais de PJM em outras instituições, verifica-se que já foram implementados no Ministério da Defesa, Polícia Militar de Pernambuco (PMPE), Polícia Militar do Piauí (PMPI), Corpo de Bombeiros Militar do Mato Grosso (CBMMT), Corpo de Bombeiros Militar de Sergipe (CBMSE) e Corpo de Bombeiros Militar do Espírito Santo (CBMES), constituindo-se assim uma tendência nacional nas Corporações militares.

A fim de suscitar a doutrina de PJM na instituição, foi elaborada por este autor uma proposta contendo o Manual de Polícia Judiciária Militar do CBMPE, a qual está disponível por meio da página virtual: 
Revista Científica do Corpo de Bombeiros Militar de Pernambuco

Artigo Publicado no Vol.07 N.19 - Julho a Dezembro 2021 - ISSN 2359-4829

Versão on-line disponível em: http://www.revistaflammae.com

http://www.rafaelqabm.wixsite.com/website. Tal proposta visa implementar normativo que regulamente os procedimentos de investigação dos crimes militares praticados por integrantes da Corporação, podendo ser a primeira legislação referente à seara criminal militar a ser aplicada no CBMPE, salientando-se que por ser uma proposta, é passiva de alterações, por meio de sugestões que podem ser expressas no site informado.

Conclui-se desta forma, que a implementação do Manual de Polícia Judiciária Militar é necessária para minimizar a problemática da falta de normatização, de forma a subsidiar os oficiais e seus auxiliares no tocante às suas atribuições inseridas na Constituição Federal de 1988, visando a qualificação técnica e profissional em prol da atividade de Polícia Judiciária Militar, seja de forma originária ou delegada.

\section{REFERÊNCIAS}

ALFERES, Eduardo Henrique. Manual de Polícia Judiciária Militar: Direito Penal e Processual Penal Militar. São Paulo: EDIPRO, 2013.

ALMEIDA, Thiago Rangel. Crime Militar e suas Particularidades. Observatório da Justiça Militar Estadual, Minas Gerais, 2019.

BRASIL. Constituição (1988). Constituição da República Federativa do Brasil. Disponível em: <http://www.planalto.gov.br/ccivil_03 /constituicao /cons tituicaocompilado.htm>, acessado em: 02 de maio de 2021.

BRASIL, Casa Civil. Decreto-Lei o 1.001, de 21 de outubro de 1969. Código Penal Militar. Disponível em: <http://www.planalto.gov.br/CCIVIL/DecretoLei/Del1001.htm>, acessado em: 22 de abril de 2021.

BRASIL, Casa Civil. Decreto-Lei 1002, de 21 de outubro de 1969. Código de Processo Penal Militar. Disponível em: <http://www.planalto .gov .br/ccivil_03 /decreto-lei/Del1002.htm>, acessado em: 22 de abril de 2021.

Decreto Lei no 13.491, de 13 de outubro de 2017. Altera o Decreto Lei $\mathbf{n}^{\circ}$ 1.001, de 21 de outubro de 1969 - Código Penal Militar. Disponível em: 
<http://www.planalto.gov.br/ccivil_03/_Ato2015-18/2017/Lei/L13491.htm\#art1>, acessado em: 26 de abril de $202 \overline{1}$.

DIAS, Marcos Antônio Negreiros; BARBOSA, João Bento Santos. Importância da Implantação do Manual de Procedimento de Polícia Judiciária Militar (PJM) na PMTO. Aturá Revista Pan-Amazônica de Comunicação. Vol. 2, n. 3, Set-Dez. 2018

ESPÍRITO SANTO. Corpo de Bombeiros Militar do Espírito Santo. Manual de Auto de Prisão em Flagrante Delito. Vitória, 2017.

GORRILHAS, Luciano Moreira. BRITTO, Cláudia Aguiar. A Polícia Judiciária Militar e seus Desafios. Porto Alegre: Núria Fabris ed., 2016.

MANOEL, Élio de Oliveira Manoel. Manual de Polícia Judiciária Militar: Teoria \& Prática. Curitiba: ATP Composições gráficas e Editora Ltda, 2005.

MATO GROSSO. Corpo de Bombeiros Militar do Mato Grosso. Manual de Polícia Judiciária Militar. Manual de Processos e Procedimentos. Cuiabá, 2017.

BRASIL. Ministério da Defesa, Comando da Marinha, Comando do Exército e Comando da Aeronáutica. Manual de Polícia Judiciária Militar. Brasília, 2019.

NEVES, Cícero Robson Coimbra. Crimes Militares Extravagantes. São Paulo: Juspodivm Ed., 2021.

PERNAMBUCO. Corregedoria Geral da Secretaria de Defesa Social. Manual de Autuação em Flagrante Delito Militar. Recife, 2018.

PERNAMBUCO. Corregedoria Geral da Secretaria de Defesa Social. Portaria do Corregedor Geral no 672. Recife, de 30 de novembro de 2015.

PERNAMBUCO. Corregedoria Geral da Secretaria de Defesa Social. Provimento Correcional no 007. Recife, de 30 de novembro de 2015.

PERNAMBUCO. Lei oㅜ 11.817, de 24 de julho de 2000. Código Disciplinar dos Militares do Estado de Pernambuco. Disponível em: < http:// legis.alepe.pe.gov.br/texto.aspx?id=1264\&tipo=TEXTOATUALIZADO>, acessa do em: 02 de maio de 2021.

PERNAMBUCO. Polícia Militar de Pernambuco. Manual de Polícia Judiciária Militar. Recife, 2018. 
PIAUÍ. Corpo de Bombeiros Militar do Piauí. Manual de Prática de Polícia Judiciária Militar. 1aㅡ Edição. Teresina, 2013.

RIBEIRO, Ney Rodrigo Lima. O crime militar na jurisprudência do Supremo Tribunal Federal (STF) e do Superior Tribunal de Justiça (STJ). Revista Direito Militar, número 124, maio/junho de 2017.

ROTH, Ronaldo João. Direito militar em movimento volume II: homenagem ao Promotor de Justiça Militar Jorge César de Assis. Aspectos militares da polícia: A polícia no Brasil. O poder de polícia. A polícia administrativa e a polícia judiciária. A atuação das Forças Armadas como polícia. Curitiba: Juruá, 2016.

SARAIVA, Alexandre José de Barros Leal. Código Penal Militar comentado: parte geral. São Paulo: MÉTODO, 2014, pp. 44 e 45.

SERGIPE. Corpo de Bombeiros Militar de Sergipe. Manual de Procedimentos de Polícia Judiciária Militar e de Polícia Administrativa Disciplinar Militar. Aracaju, 2014. 